$\underline{\underline{\beta}}=$ 离

\title{
Management outcome of obstructed kidney disease due to stones: experience from Gezira hospital for renal disease and surgery, Sudan
}

\author{
Nadir Ibrahim Abdon Fadol ${ }^{1}$, Mohmmed El Imam Mohammed ${ }^{2}$, \\ Sami Mahjoub Taha ${ }^{3}$, Mohamed D Awadalla Gismalla ${ }^{*}$ \\ ${ }^{1}$ Urologist, Sudan Medical Specialization Board, Sudan \\ ${ }^{2}$ Professor of Urology, Department of Surgery, University of Gezira, Sudan \\ ${ }^{3}$ Associate Professor, Department of Surgery, University of Gezira, Sudan \\ ${ }^{4}$ Assistant Professor, Department of Surgery, University of Gezira, Sudan \\ *Corresponding author E-mail: mohadaff22@gmail.com
}

\begin{abstract}
Background: Obstructive nephropathy which caused by stones is a burden problem in developing countries associated with late presentation and a lot of complications.

Objective: This study was done to evaluate the outcome of management of obstructed kidney due to stones at Gezira hospital for renal disease \& surgery.

Material and Methods: This is prospective cross-sectional hospital-based study. All patients who presented with obstructed kidneys and fulfill the criteria were included. Constructed flow chart was used to collect data. Then data was analyzed to detect the dependent $\&$ independent variable. Relation with P-value $<0.05$ are considered significantly.

Result: 140 patients are included. Duration of Presenting symptoms was 9 weeks or more in 99 patients, 5-8 weeks in 11 patients, 2-4 weeks in 6 patients, and less than two weeks in 30 patients. It is strongly related to post-intervention serum creatinine $(\mathrm{P}$-value $=0.009)$. Common site of stone is ureter (58 patients) and renal pelvis (54 patients) significantly associated with recovery (P-value 0.009$)$. An urgent intervention was done to 69 patients. Definitive treatments were Open surgery, endoscopic procedure (URS), or both with rate 65(46.4\%), $57(40.7 \%)$, and 10(7.2\%) respectively. In 5.7\% ( $\mathrm{n}=8$ patients) endoscopic procedure (URS) was failed. Postoperative follow up (after 6 weeks or after removal of stent) $95.7 \%$ ( $\mathrm{n}=134$ patients) were free from symptoms, and there were no clinical signs in all patients post intervention.
\end{abstract}

Conclusion: late presentation and site of obstructed kidney stone can predict the complication and affect the outcome.

Keywords: Renal Stone; Ureteric Stone; Obstructive Nephropathy.

\section{Introduction}

Urinary stones are very common among men and women with estimated prevalence among the population of $2-3 \%$ and an estimated lifetime risk of $12 \%$ for white males (Menon et al 1998) and 5-6\% for white females (Wilkinson 2001). The life time recurrence rate is approximately 50\% (Bihl \&Meyers 2001). The interval between recurrences is variable, with approximately $10 \%$ within one year, $35 \%$ within five years, and $50 \%$ within 10 years (Wilkinson 2001). Even a single kidney stone episode was associated with a significant increase in the likelihood of adverse renal outcomes, including ESRD (Alexander et al 2012).

Considerable progress has been made in the medical and surgical management of stones over the past 20 years. The introduction and continuous development of percutaneous nephrolithotomy, the achievement of extracorporeal shock-wave lithotripsy, and the advancements in ureterorenoscopy have led to a revolution in the interventional management urolithiasis (Horneck et al 2009).

Hypertension and obstructive uropathy are the leading causes of end-stage renal disease in Gezira state in Sudan (Elsharif \& Elsharif 2011). Urolithiasis is common throughout the Sudan except for the southern region where it is rare. The latter region is cooler and decidedly moister than the other provinces during the hot months of the year (May-October). In the Northern provinces, urolithiasis is commoner in areas with lower relative humidity (Kambal et al 1979). Acute Kidney Injury (AKI) is an important cause of morbidity and mortality in developing countries .An $8.5 \%$ of AKI in Sudanese Children due to urinary tract obstruction by stone (Abdelraheem et al 2014).Incidence of urinary stones in the industrialized world is associated with improved standards of living (mainly including the high dietary intake of proteins and minerals) as well as with race, ethnicity and region of residence (Stamatelou et al 2003). Stones which cause obstructive nephropathy, were found more common in the kidney than in the ureter (Prstojevic et al 2014).Renal and ureteral stones are a common problem in primary care practice (Fwu et al 2013). The asymptomatic phase is more likely to persist in those who have never had a clinical episode of renal colic (Glowacki et al 1992).

Stone disease is one of the most common urological diseases in Sudan. Gezira hospital for renal disease \&surgery is the only specialized urological hospital outside Khartoum, at which stone disease is $3^{\text {rd }}$ cause of renal impairment. Early diagnosis $\&$ intervention can preserve the renal function and accelerate renal recovery, accordingly outcome of intervention at Gezira hospital for renal disease \& surgery need to be evaluated. This study was done 
to evaluate the outcome of management of obstructed kidney due to stones at Gezira hospital for renal disease \&surgery.

\section{Material \& methods}

\subsection{Over view}

This is prospective cross-sectional hospital-based study. All patients who presented with obstructed kidneys (physiological and /or anatomical damage to the kidney due to obstruction caused by stones) during research period ( $1^{\text {st }}$ of March 2015 to $30^{\text {th }}$ of Sep 2015) and was managed at Gezira hospital for renal disease \& surgeries were included. Furthermore, patients should have been regular follow up (on Day ten and after six weeks for open intervention and endoscopic procedures with or without stent). We exclude any patients presented with obstructed kidney due to other causes of obstruction (e.g. tumor, stricture, etc.), or those we missed their follow up. There are 140 patients who fulfill our criteria by using purposeful non-probability sampling technique.

\subsection{Peri-operative evaluation}

Patients were initially assessed by adequate history, examination and investigations, which include serum creatinine (normal serum creatinine $=1.6 \mathrm{mg} / \mathrm{dl}$ ), ultrasound KUB was done routinely for all patients, CT-KUB or intravenous pyelogram were done for the most of the patients to confirm the diagnosis and to determine the level and site of the stone. Retrograde and antegrade Pyelography were done in a fewer number of patients. Surgery (open or endoscopic) was done by consultant, specialist or registrar. Urgent intervention such as percutaneous nephrostomy (PCN), ureteric stent or dialysis were done and admission if indicated, then definitive management either open surgery (pyelolithotomy, nephrolithotomy or ureter lithotomy) or endoscopic (ureteroscopy plus holmium Laser fragmentation) with or without ureteric stent (DJ). Informed consent was taken from all the patients before surgery. All procedures were done under general anesthesia except lower ureteric stone in adult done under spinal anesthesia. In open surgery patients admitted for three to five days postoperative and discharge after removal of drain but patients who underwent URS usually discharge after 24 hours postoperatively. Patients came back to the hospital after ten days from the day of surgery and then after six weeks to remove uretericstent(DJ) and to follow up the patients.

Patients were followed during this visit with history, examination, S.creatinine and image (KUB X ray or ultrasound ).The successful of intervention means no obstruction and recovery of serum creatinine either completely ( S.creatinine less than $1.6 \mathrm{mg} / \mathrm{dl}$ ) or partially ( decrease in S.creatinine in compare with reinnervations. creatinine and became not need dialysis )recover.

\subsection{Data analysis and statistics}

Constructed flow chart was use to collect data. Then data was an analysis by using computer program Statistical Package for Social Sciences (SPSS), dependent $\&$ independent variable will be considered as significant if $\mathrm{P}$-value $<0.05$.

\section{Result}

The total number of the study group was 140 patients. The mean age was $42.17 \pm 16.975$ year. About $62.9 \%$ ( $n=88$ patients) were males, and $37.1 \%(n=52$ patients) were females, with male: female ratio $1.7: 1 \mathrm{In}$ this study, we found that, the duration of presenting symptoms is nine weeks or more in 99 (66.47\%)patients, $5-8$ weeks in $11(7.99 \%), 2-4$ weeks in $6(4.3 \%)$, and less than two weeks in $30(21.4 \%) .100 \%$ of the patients presented within four weeks or less were completely recovered from renal impairment (Table 1). The anatomical site of obstructed stones was found in the ureter $58(41.4 \%)$, followed by renal pelvis stones $54(38.6 \%)$. After treatments, complete renal recovery occurs in $60 \%$ of patients having ureteric stones and only in $28.5 \%$ of patients having renal pelvis stones (Table 1 ).

Regarding level of obstructions $45.0 \%$ ( $n=63$ patients) was the upper ( renal or upper ureter) urinary tract and unilateral , $22.1 \%$ $(\mathrm{n}=31$ patients) in the lower (lower ureter) and unilateral , $16.4 \%$ $(\mathrm{n}=23$ patients) in the upper urinary tract and bilateral , $7.9 \%$ $(\mathrm{n}=11$ patients) in upper plus lower plus bilateral , $5 \%(\mathrm{n}=7$ patients) in lower and bilateral and 3.5\% ( $\mathrm{n}=5$ patients )in upper plus lower plus unilateral. The degree of obstruction in61.4\% ( $\mathrm{n}=86$ patients) were partial and chronic obstructions, $22.1 \%(\mathrm{n}=31 \mathrm{pa}-$ tients) were complete and chronic obstructions, $10.7 \%(\mathrm{n}=15 \mathrm{pa}-$ tients) were acute and partial obstructions and $5.7 \%$ ( $\mathrm{n}=8$ patients) cause acute and complete obstructions. $100 \%$ of Patients who presented with acute obstruction (completely or partially) were completely recovered from renal impairment.

The urgent intervention was done in $49.2 \%$ ( $\mathrm{n}=69$ patients). $65.3 \%$ ( $\mathrm{n}=45$ patients) was $\mathrm{PCN}$, in $17.4 \%(\mathrm{n}=12$ patients) was DJ stent insertion, in $10.2 \%$ ( $\mathrm{n}=7$ patients) was $\mathrm{PCN}$ and dialysis, in $2.8 \%$ $(\mathrm{n}=2$ patients) was DJ stent and dialysis insertion and in $4.3 \%$ ( $n=3$ patients) was PCN and DJ stent insertion. $50 \%$ of patients with PCN insertion were completely recover and $50 \%$ were partially recover from renal impairment and same result with DJ stent insertion (Table 1).

Table 1: Outcome of Management of Obstructed Kidney Due to Stones: Duration of Symptoms, Site of Obstruction, and Urgent Intervention Post Intervention S. Creatinine

\begin{tabular}{|c|c|c|c|c|c|c|}
\hline \multirow[t]{2}{*}{ Variables } & & \multicolumn{3}{|c|}{ Post intervention S. Creatinine } & \multirow[t]{2}{*}{ Total } & \multirow[t]{2}{*}{ P Value } \\
\hline & & Normal & Partial Recovery & $\begin{array}{l}\text { Complete } \\
\text { Recovery }\end{array}$ & & \\
\hline \multirow{4}{*}{ Duration of symptoms } & $<2$ Weeks & 26 & 0 & 4 & 30 & 0.009 \\
\hline & 2 - 4 Weeks & 3 & 0 & 3 & 6 & \\
\hline & 5 - 8 Weeks & 10 & 1 & 0 & 11 & \\
\hline & $\geq 9$ Weeks & 65 & 17 & 11 & 93 & \\
\hline \multirow{7}{*}{ Site of obstruction } & Renal Pelvis & 40 & 10 & 4 & 54 & 0.009 \\
\hline & Ureteral & 48 & 4 & 6 & 58 & \\
\hline & Renal Pelvis + Ureteral & 7 & 1 & 1 & 9 & \\
\hline & PUJ + Ureteral & 5 & 2 & 5 & 12 & \\
\hline & Renal Pelvis+ PUJ & 1 & 1 & 0 & 2 & \\
\hline & VUJ & 3 & 0 & 1 & 4 & \\
\hline & Renal Pelvis+ VUJ & 0 & 0 & 1 & 1 & \\
\hline \multirow{6}{*}{$\begin{array}{l}\text { Urgent } \\
\text { intervention }\end{array}$} & $\mathrm{PCN}$ & 26 & 9 & 10 & 45 & 0.000 \\
\hline & DJ stent & 10 & 1 & 1 & 12 & \\
\hline & No Urgent intervention & 68 & 2 & 1 & 71 & \\
\hline & $\mathrm{PCN}+\mathrm{DJ}$ stent & 0 & 0 & 3 & 3 & \\
\hline & Dialysis+ PCN & 0 & 5 & 2 & 7 & \\
\hline & Dialysis+ DJ stent & 0 & 1 & 1 & 2 & \\
\hline
\end{tabular}


Open surgery (Nephrolithotomy or ureterolithetomy) was done for $46.4 \%$ ( $n=65$ patients) as successful definitive treatments, in $40.7 \%$ ( $\mathrm{n}=57$ patients) was successfully endoscopic procedure (URS), in $7.2 \%$ (n=10patients) was successful open and endoscopic. In $5.7 \%(\mathrm{n}=8$ patients) endoscopic procedure (URS) was failed. Postoperative follow up (after one and half month or after removal of stent) $95.7 \%$ ( $\mathrm{n}=134$ patients) were free from symptoms, and there were no clinical signs in all patients post intervention.

Postoperative follow up 50\% ( $\mathrm{n}=18$ patients) of patients who had high serum creatinine were completely recover from the renal impairment and 50\% ( $\mathrm{n}=18$ patients) were partially recover from the renal impairment and their S.creatinine ranged from 1.7 to $5.7 \mathrm{mg} / \mathrm{dl}$. There is no change in renal recovery after the definitive intervention in compared with result after post urgent intervention (Table 2).Post definitive intervention 10\% ( $\mathrm{n}=14$ patients) had residual stones, $71.5 \%(\mathrm{n}=10)$ of them underwent ESWL, 21.4\% $(n=3$ patients) of them underwent URS and $7.1 \%$ ( $n=1$ patients) of them underwent open surgery and all of them were stone free following second definitive intervention.

Table 2: Outcome of Management of Obstructed Kidney Due to Stones: Follow Up After One and Half Month or after Removal of Stent of the S. Creatinine in 140 Patients at GHRDS

\begin{tabular}{ll}
\hline S. Creatinine & Frequency $(\%)$ \\
\hline Normal & $104(74.4 \%)$ \\
Partial Recovery & $18(12.8 \%)$ \\
Complete Recovery & $18(12.8 \%)$ \\
total & $140(100 \%)$ \\
\hline
\end{tabular}

\section{Discussion}

In this study, we found that stone disease as a cause of obstruction was found to be the major determinant of renal recovery after obstruction. In this study we found that stone disease as a cause of obstructive nephropathy was commoner among male than female which was compatible with other studies (Soucie 1994, Menon et al 1998, Pearle2005, Lieske2006, Scales2007). The duration of symptoms was inversely related to post-intervention serum creatinine which was statistically highly significant $(\mathrm{P}$ value $=0.009)$. In about $74.4 \%$ of the patients pre-intervention had normal serum creatinine because about $70 \%$ were unilateral obstructed and $72 \%$ were partially obstructed, and $25.6 \%$ of the patients had high serum creatinine which was comparable with study done at Texas (Teichman et al 1995) in which they found about $28 \%$ of the patients had high serum creatinine.

In preoperative assessment of the patients at Gezira hospital for renal disease \& surgery they follow the European guide line in requesting investigations for the stones disease and was obviously appear in around $70 \%$ of the patients were assessed by CT.KUB and $25 \%$ of the patients were referred to us with I.V.U. Abdominal ultrasound was done for all patients as initial investigation and that explained by most of patients were referred from medical department and they use to request abdominal ultrasound routinely as initial investigation for loin pain. Abdominal ultrasound was requested alone in about $5 \%$ of the patients for pregnant ladies and the intervention was accordingly either DJ stent insertion or PCN. In this study we found that ureteric stones $(41.4 \%)$ was more common than renal stones $(38.6 \%)$ as a cause of obstructive nephropathy and in compare with study done in Bonsnia (Prstojevic et al 2014) they found that renal stones $(76.3 \%)$ was more than ureteric stones $(23.7 \%)$ and this variation can be explained by most of our patients could had secondary ureteric stone due to delayed presentation. We found that post urgent intervention complete renal recovery (serum creatinine) was more in ureteric stone $60 \%$ (6 out of 10 patients) than in renal stone $28.5 \%$ ( 4 out of 14 patients), most probably due to concomitant or secondary infection in renal stones, this relation between site of stone and renal recoverability was found statistically significant $(P$ value $=0.009)$.
Most of studies in the literature review they talk about PCNL as standard modality of surgical intervention in renal stones more than $2 \mathrm{~cm}$, in our center this procedure was not done because of technical problems so all renal stones that amenable for PCNL they managed by open renal surgery with $100 \%$ successful rate regarding post intervention serum creatinine (no obstruction and partially or complete renal recovery).

The successful rate of URS about $90 \%$ (75patients) as single procedure or combined with open surgery and this outcome is acceptable in compare with other studies like study conducted in Pakistan(Fasihuddin \& Hasan 2002) with successful rate of URS was $92 \%$. In $5.6 \%$ of the patients who underwent URS and they were failed to attack the stone primarily DJ stent was inserted and redo URS was done by senior staff within one month and was successful. Following urgent intervention $50 \%$ (18 patients) were completely recovered from renal impairment and the rest were partially recovered. We found there was close relation between urgent intervention and recovery of serum creatinine which was statistically significant $(\mathrm{P}$ value $=0.000)$. The effect of DJ-stent or PCN-tube insertion on renal recovery was equal; a similar study conducted in Egypt in 2015 found that serum creatinine levels return to the normal level within 72 hours after initial urinary drainage in both PCN-tube and JJ-stent groups (ElSheemy2015).

\section{Conclusion}

The outcome of management of obstructed kidney due to stones at Gezira hospital for renal disease \& surgery was found to be acceptable and comparable to other international centers. The ureter was the commonest site of obstruction. The level of education and misleading in primary health subset expressed the greater factor in delaying from having optimal treatment. The time of intervention and degree

\section{References}

[1] Abdelraheem M, Ali E T, Osman R, Ellidir R, Bushara A, Hussein R \& Abu-Aisha H (2014) Outcome of acute kidney injury in sudanese children-an experience from a sub-Saharan African unit. Peritoneal Dialysis International, 34(5), 526-533. https://doi.org/10.3747/pdi.2013.00082.

[2] Alexander R T, Hemmelgarn B R, Wiebe N, Bello A, Morgan C, Samuel S\& Tonelli M (2012) Kidney stones and kidney function loss: a cohort study. https://doi.org/10.1136/bmj.e5287.

[3] Bihl G, \& Meyers a (2001) recurrent renal stone disease-advances in pathogenesis and clinical management. The Lancet, 358(9282), 651-656. https://doi.org/10.1016/S0140-6736(01)05782-8.

[4] Elsharif M E, \& Elsharif E G (2011) Causes of end-stage renal disease in Sudan: A single-center experience. Saudi Journal of Kidney Diseases and Transplantation, 22(2), 373376.http://www.sjkdt.org/text.asp?2011/22/2/373/77650

[5] ElSheemy M S, Shouman A M, Shoukry A I, ElShenoufy A, Aboulela W, Daw K \&Badawy H (2015) Ureteric stents vs percutaneous nephrostomy for initial urinary drainage in children with obstructive anuria and acute renal failure due to ureteric calculi: a prospective, randomised study. BJU international, 115(3), 473-479. https://doi.org/10.1111/bju.12768.

[6] Fasihuddin Q \&Hasan A T (2002) Ureteroscopy (URS): an effective interventional and diagnostic modality. JPMA. The Journal of the Pakistan Medical Association, 52(11), 510-512.

[7] Fwu C W, Eggers P W, Kimmel P L, Kusek J W, \&Kirkali Z (2013) Emergency department visits, use of imaging, and drugs for urolithiasis have increased in the United States. Kidney international, 83(3), 479-486. https://doi.org/10.1038/ki.2012.419.

[8] Glowacki L S, Beecroft M L, Cook R J, Pahl D \& Churchill D N (1992) The natural history of asymptomatic urolithiasis. The Journal of urology, 147(2), 319-321.

[9] Honeck P, Wendt-Nordahl G, Krombach P, Bach T, Häcker A, Alken P, \& Michel M S (2009) Does open stone surgery still play a role in the treatment of urolithiasis? Data of a primary urolithiasis center. Journal of Endourology, 23(7), 1209-1212. https://doi.org/10.1089/end.2009.0027. 
[10] Kambal A, Wahab E M, \&Khattab A H (1979) Urolithiasis in Sudan. Geographical distribution and the influence of climate. Tropical and geographical medicine, 31(1), 75-79.

[11] Lieske J C, De La Vega L P, Slezak J M, Bergstralh E J, Leibson C L, Ho K L \&Gettman M T. (2006). Renal stone epidemiology in Rochester, Minnesota: an update. Kidney international, 69(4), 760764. https://doi.org/10.1038/sj.ki.5000150.

[12] Menon M (1998) Urinary lithiasis: etiology, diagnosis, and medical management. Campbell's urology. In: Walsh PC, editor. Campbell's Urology. 7th edition, Philadelphia: Saunders, pp. 2661-2733.

[13] Pearle M S, Calhoun E A, Curhan, G C \& Urologic Diseases of America Project. (2005). Urologic diseases in America project: urolithiasis. The Journal of urology, 173(3), 848-857. https://doi.org/10.1097/01.ju.0000152082.14384.d7.

[14] Prstojevic J K, Junuzovic D, Hasanbegovic M, Lepara Z \&Selimovic M (2014) Characteristics of Calculi in the Urinary Tract. Materia $\quad$ socio-medica, 26(5), 297-302 https://doi.org/10.5455/msm.2014.26.297-302.

[15] Scales C D, Curtis L H, Norris R D, Springhart W P, Sur R L, Schulman K A \& Preminger G M (2007) Changing gender prevalence of stone disease. The Journal of urology, 177(3), 979-982. https://doi.org/10.1016/j.juro.2006.10.069.

[16] Stamatelou K K, Francis M E, Jones C A, Nyberg L M, \&Curhan G C (2003) Time trends in reported prevalence of kidney stones in the United States: 1976-19941. Kidney international, 63(5), 18171823. https://doi.org/10.1046/j.1523-1755.2003.00917.x.

[17] Soucie J M, Thun M J, Coates R J, McClellan W, \& Austin H (1994) Demographic and geographic variability of kidney stones in the United States. Kidney international, 46(3), 893-899. https://doi.org/10.1038/ki.1994.347.

[18] Teichman J M, Long R D, \& Hulbert J C (1995) Long-term renal fate and prognosis after staghorn calculus management. The Journal of urology, 153(5), 1403-1407. https://doi.org/10.1016/S00225347(01)67413-5.

[19] Wilkinson H (2001) Clinical investigation and management of patients with renal stones. Annals of clinical biochemistry, 38, 180187. https://doi.org/10.1258/0004563011900623. 